\title{
ВMJ Global Health Setting the research and implementation agenda for equitable access to surgical care in South Africa
}

\author{
Sarah Rayne, ${ }^{1}$ Sule Burger, ${ }^{2}$ Stephanie Van Straten, ${ }^{1}$ Bruce Biccard, ${ }^{3}$ \\ Mathume Joseph Phaahla, ${ }^{4}$ Martin Smith ${ }^{1}$
}

To cite: Rayne S, Burger S, Straten SV, et al. Setting the research and implementation agenda for equitable access to surgical care in South Africa. BMJ Glob Health 2017;2:e000170. doi:10.1136/ bmjgh-2016-000170

Received 29 August 2016 Accepted 6 February 2017

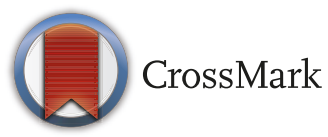

${ }^{1}$ Department of Surgery, Faculty of Health Sciences, University of the Witwatersrand, Johannesburg, South Africa ${ }^{2}$ Department of Surgery, Tembisa Hospital, Johannesburg, South Africa ${ }^{3}$ Department of Anaesthesia and Perioperative Medicine, University of Cape Town, Cape Town, South Africa

${ }^{4}$ Office of the Deputy Minister, Pretoria, South Africa

Correspondence to Dr Sarah Rayne; sarah.rayne@wits.ac.za

\section{ABSTRACT}

South Africa is an upper-middle-income country with widespread social and geographical inequality of surgical provision. The National Forum on Surgery and Anaesthesia in South Africa brought together various stakeholders, including government, societies, academic clinicians and the biomedical industry, to define the core strategy for a national surgical plan.

During the forum, presentations and breakaway workshops explored and reported the challenges and opportunities these stakeholders may have in sustaining and improving surgical provision in South Africa. We present the recommendations of these reports with a literature review and other recent reports from organisations involved in healthcare systems in South Africa.

We acknowledge the importance of access to safe and affordable surgery for all as a core component of healthcare provision for South Africa. The proposed core strategies for a South African National Surgical Plan to achieve these goals are the following. First, research will focus on high-quality interdisciplinary collaborative research and audit, which addresses the Global Surgery indices, adopts internationally consistent data points and focuses particularly on maternal mortality and the 'Bellwether procedures'. Second, workforce and training must be tailored to the country's specific surgical needs, based on a primary healthcare and district hospital model, which is supported by government and academic organisations. Third, the surgical infrastructure and service delivery needs to be strengthened by the district hospital.

Finally, strong leadership with appropriate financial support by healthcare managers who partner with clinicians both locally and nationally is needed to achieve these objectives.

\section{INTRODUCTION}

Access to safe and affordable surgical care is starting to be recognised as an 'indivisible part of improving global healthcare'. ${ }^{2}$ The 68th World Health Assembly passed resolution A 68/15 on Strengthening Emergency and Essential Surgical Care and Anaesthesia as a Component of Universal Health Coverage. ${ }^{3}$ This report showed that surgically treatable diseases have a significant effect on the global burden of disease, disability and economic

\section{Key questions}

What is already known about this topic?

- Safe surgical care has been recognised as an indivisible part of improving global healthcare by the international governmental and health communities.

- South Africa is an upper-middle-income country with an inequitable distribution of healthcare resources both geographically and between public and private sectors and no current national surgical plan.

What are the new findings?

- This work describes the key messages identified in the first National Forum on Surgery and Anaesthesia in South Africa in its progress towards a national surgical plan for this upper-middle-income country.

- This report about equitable access in surgical carewas compiled from workshops of multidisciplinary groups of experienced in-country clinicians and public health experts in addition to published and unpublished information, and may be equally applicable to other low-income and middleincome countries.

- In the pathway to strengthened and reformed surgical care provision in South Africa, this report has comprehensively summarised the fundamental problems and advanced solutions grounded in collective years of experience in this field.

\section{Recommendations for policy}

- With its broad base of stakeholder involvement, this report will underpin the future strategy to develop national indicators of surgical care and a national surgical plan.

- It can act as a reference for clinicians in many lowincome and middle-income countries responding to the Lancet Commission on Global Surgery and embarking on this important reform in their own situations.

impact of health. The Lancet Commission on Global Surgery (LCoGS), published in 2015, showed the value of strengthening the place of surgery in global health. ${ }^{4}$ As part of the five key messages, LCoGS found that 5 billion of the world's population cannot access safe, affordable surgical care when needed, 
including 9 out of 10 people in low/middle-income countries (LMICs). ${ }^{4}$ Further, the World Bank highlighted surgery as a priority in its 'Disease Control Priorities in Developing Countries' (DCP) publication, extending coverage from scattered references in the first edition (DCP1) to one volume of DCP3. ${ }^{1}$

Each of these initiatives emphasised surgery as a basic priority and highlighted how surgery and anaesthesia should be embedded into healthcare systems to ultimately improve health, welfare and economic development. In South Africa, the right of access to healthcare is enshrined in Chapter Two of the constitution. ${ }^{5}$ Following the dismantling of apartheid, South Africa has had more than two decades of democracy where successive administrations have sought a 'rolling back [of] the shadow of history and broadening opportunities for all'. ${ }^{6}$ The health of the nation has been addressed in a number of governmental policy documents, including a National Development Plan (NDP) for 2030, Negotiated Service Delivery Agreement and, most pertinently for the health sector, the Medium-Strategic Plan for 2014-2019, which has been designed to address the Department of Health's vision of 'A Long and Healthy Life for All South Africans' with staggered implementation to address health priorities towards $2030{ }^{7}$

In addition to the priorities of an HIV-free generation, reducing infant mortality and raising life expectancy, the NDP aims to 'significantly reduce the [quadruple] burden of disease' in the country. ${ }^{78}$ It also expressly acknowledges that there are no 'quick fixes' to achieve these priorities but noted the importance of addressing the social determinants that affect health and diseases, strengthening the health system and improving human resources in the health sector, all of which are pressing concerns for surgical services in South Africa. As stated by the South African Deputy Minister of Health, 'This objective cannot be fully achieved without recognizing the importance of the universal access to safe and affordable surgical and anaesthetic care. Hence it is imperative that improving access to surgery and anaesthetic care should be part of the global health agenda'.

Following the publication of the LCoGS, and to coincide with the South African launch of the LCoGS, a National Forum on Surgery and Anaesthesia in South Africa (NFSASA) was held at the University of the Witwatersrand (Wits) in December 2015 in Johannesburg. This forum brought together stakeholders in health and other interested parties, including government, societies, academics clinicians and the biomedical industry, to discuss the implementation of this progressive initiative in South Africa. Over 70 attendees contributed, primarily representing South Africa but also from countries in Southern and West Africa and the USA. Through presentations and series of breakaway workshops based on some of the WHO health system building blocks, ${ }^{9}$ the NFSASA first examined the current position of timely access to safe high-quality surgical service in South Africa and its status in the existing model of service delivery. From there, participants endeavoured to map out new pathways for this integration of surgical care into the primary care agenda through a national surgical plan, using the LCoGS framework. Key research and implementation messages were identified.

Following the meeting, the authors undertook an electronic search from all available published literature, unpublished reports and available policy documents to support and develop these key messages further. To ensure that more limited or local studies were not overlooked, we also approached the national surgery, surgical research and anaesthetic societies for unpublished conference abstracts in the field. The current position of surgery in South Africa together with these key messages, set in context and with future strategies resulting from the meeting, is discussed here.

\section{RECOGNISING SURGICAL CARE AS A PUBLIC HEALTH AND ECONOMIC PRIORITY}

Surgical conditions account for about $30 \%$ of the global burden of disease. Mortality from surgically preventable disease exceeds mortality from communicable diseases worldwide. In 2010, an estimated 16.9 million lives (32.9\% of all deaths worldwide) were lost from conditions needing surgical care. ${ }^{4}$ This figure well surpassed the number of deaths from HIV/AIDS (1.46 million), tuberculosis ( 1.20 million) and malaria ( 1.17 million) combined, ${ }^{10}$ yet the urgent need for surgical care in the world's poorest regions is still widely unrecognised.

The spectrum of surgically preventable disease is broad and affects all parts of the population. In maternal care, access to safe caesarean sections is critical and cost-effective in reducing both neonatal and maternal mortality and long-term disability such as obstetric fistulae. ${ }^{11-13}$ In the 49 countries identified by WHO in 2008 with inadequate provision of caesarean sections, it was estimated that obstructed labour and subsequent maternal mortality cost 1.1 million disability-adjusted life-years (DALYs) per year globally. ${ }^{11}$ Within cancer care, an estimated 14.1 million new cancer cases occurred in 2012 worldwide, ${ }^{14}$ more than 8 million of these cancers occur in LMICs (increasing from $15 \%$ of the world's cancer burden in 1970 to an estimated $70 \%$ in 2030).${ }^{15}$ In South African women, the most common cancers and leading causes of cancer death are breast and cervix cancers, with an age-standardised incidence rate of 26.96 and 22.33 per 100000 , respectively. ${ }^{16}$

A further significant area of surgical need is in trauma care. Trauma was the cause of $37.2 \%$ of operations in a recent multicentre surgical outcomes study undergoing intraperitoneal surgery. ${ }^{17}$ Despite a recent reversal in the trend of the disease burden caused by injuries (both road injuries and interpersonal violence), the trauma caseload incidence of 1290 per 100000 from the Kwa-Zulu Natal province compares to rates from the developed world of $13-20$ per $100000 .{ }^{18}$ Both road injuries and interpersonal violence remain in the top 10 ranking of years of life lost 
in every province in the country in the most current National Burden of Disease study (2012) ${ }^{19}$ and absorbs significant financial resources. ${ }^{18}$

To manage this burden of surgical disease and common to all, these areas of surgical provision are the key reliance on appropriately trained surgeons being enabled, through systems, supporting healthcare personnel and facilities, to carry out surgeries. Across all LMICs, the LCoGS reveals that approximately 2 million more specialist healthcare providers would be required to reach the goal of 20-40/100 000 specialist providers and a minimum prescribed surgical volume of 5000 surgeries per 100000 population by $2030 .{ }^{420}$ With 5227 surgeries per 100000 population, South Africa is placed 44th out of 192 countries and has 11.53 specialists per $100000,{ }^{21}$ but the country's relatively good ranking in surgical provision belies a deep divide in access to affordable surgical care. Despite a healthy $8.8 \%$ gross domestic product (GDP) being spent on health in South Africa, there is marked disparity between public and private sectors in the country. Fifty-two per cent of the total healthcare spending occurs in the private sector, accessible to only $16 \%$ of the population, whereas only $30.6 \%$ of doctors (including almost all junior doctors, but far fewer senior clinicians) and $45.1 \%$ of nurses work in the public sector, responsible for the care of $84 \%$ of the population. ${ }^{22}$

This disproportion of healthcare workers between public and private sectors nationally is further compounded by healthcare inequities of access to specialist care and health technology, infrastructure and available services. ${ }^{23}$ The disparity affects most significantly on the poor, particularly rural poor, in terms of lives lost and failure to prevent long-standing illness and disability. ${ }^{24}{ }^{25}$ The LCoGS highlighted that globally each year, at least 77.2 million DALYs could be averted by basic, life-saving surgical care ${ }^{4}$ with the burden of these untreated surgical conditions falling heaviest on individuals living in LMICs. ${ }^{26}$ In South Africa, the loss of family income through disability (either the patient's income or that of relative's providing care) perpetuates inequality, poverty and unemployment in low-income and rural populations. Although costs are not available for South Africa alone, when considered on a global scale, these failures to adequately address the needs of populations in LMICs, in surgical service, personnel and disease burden of surgical conditions will cost up to $\$ 12.3$ trillion dollars in lost productivity. This translates into $2 \%$ of GDP growth annually between 2015 and $2030,{ }^{4}$ which will contribute to a failure of economic development, environmental sustainability and social inclusion as addressed by the WHO Sustainable Development Goals worldwide and locally in South Africa.

A further barrier in access to care is the prioritised arrangement around primary health clinics (PHCs) by government health systems in South Africa. These are the encouraged entry point for patients and often the only level free of charge at the point of use. This model is designed to serve many community-manageable conditions and act as a gatekeeper to specialist care. During the re-engineering of this process in the last 10 years, there has been a documented failure to integrate this system with district hospitals and strengthen these district facilities. ${ }^{27}$ Because surgery at district or tertiary level is not integrated into the PHC model of primary healthcare, patients can incur multiple direct and indirect delays navigating their course beyond the PHC to surgical diagnosis and ultimately to timely surgery. As the Pan African Association of Surgeons has noted in their statement on the delivery of surgical services in sub-Saharan Africa, "the provision of surgical services in Sub-Saharan Africa should be in alignment with the principle of Primary Healthcare in order to enhance the health and well-being of all its citizens. ${ }^{, 28}$

Integrating surgery into the system of PHC requires a national surgical plan to be developed by stakeholders from government and surgical care providers. Discussed by governmental stakeholders at the NFSASA was the use of building blocks tailored from the WHO framework $^{9}$ in addressing the major domains of essential national surgical care provision, which are information and research, workforce, infrastructure and health technology, service delivery, leadership and management, and financing. Such pronounced changes to surgical healthcare delivery in the country will require radical rather than incremental changes in surgical service provision, ranging from PHCs, community clinics to tertiary level hospital care. It will require stakeholder involvement, including government, professional associations, universities and the perioperative community of healthcare workers.

\section{KEY MESSAGES FOR CHANGE IN SURGICAL CARE IN SOUTH AFRICA \\ Information and research: Local high-quality collaborative research is required to inform radical changes in surgical provision}

In South Africa, there is a need to accurately identify the current surgical provision in the country and then set in place methods of audit that will allow a measurement of change and success. Global surgery research requires internationally standardised definitions of both risk factors and outcomes in order to be able to compare results across countries. Using standards such as the LCoGS six indicators ${ }^{4}$ and adapting them to the South African context allow this audit. Table 1 summarises these global indicators and their application for South Africa. Current research effort aiming to address these indicators that arose from the NFSASA is further summarised in the table.

Within the country, standardised national methodology will allow comparison over time and across hospitals. Some of the strategies required to advance this agenda are summarised in box 1. Following the NFSASA, with the aim of a National Surgical Plan in mind, a Programme for Equitable Access to Surgical Care (PEASC) was 
Table 1 Indicators of assessment to safe and affordable surgical and anaesthesia care, their application and route of assessment in South Africa

\begin{tabular}{|c|c|c|c|c|}
\hline $\begin{array}{l}\text { LCoGS } \\
\text { indicator }\end{array}$ & $\begin{array}{l}\text { LCoGS time bound } \\
\text { target for } 2030\end{array}$ & $\begin{array}{l}\text { Time bound target adapted } \\
\text { for South Africa } \\
\text { (calculated on a population } \\
\text { of } 54 \text { million) }\end{array}$ & Current status of data & $\begin{array}{l}\text { Plans arising from the } \\
\text { NFSASA and research } \\
\text { networks in South Africa }\end{array}$ \\
\hline $\begin{array}{l}\text { Access to } \\
\text { essential } \\
\text { surgery within } \\
2 \text { hours }\end{array}$ & $\begin{array}{l}\text { A minimum of } \\
80 \% \text { coverage of } \\
\text { essential surgical } \\
\text { and anaesthesia } \\
\text { services per country }\end{array}$ & $\begin{array}{l}80 \% \text { of the population within } \\
2 \text { hours travel (or } 40 \mathrm{~km} \text { as } \\
\text { the crow flies) of a district } \\
\text { hospital capable of surgical } \\
\text { services }\end{array}$ & $\begin{array}{l}\text { Population coverage } \\
\text { unknown. }\end{array}$ & $\begin{array}{l}\text { SAMaSS is a current } \\
\text { project through PEASC } \\
\text { in collaboration with } \\
\text { StatsSA to map hospitals } \\
\text { capable of carrying out } \\
\text { surgical services. Using } \\
\text { census data, population } \\
\text { characteristics of those } \\
\text { covered and uncovered } \\
\text { will be described. Through } \\
\text { design of an interactive } \\
\text { map, identification of sites } \\
\text { suited for upgrading to } \\
\text { best attend underserved } \\
\text { populations can be } \\
\text { identified. }\end{array}$ \\
\hline $\begin{array}{l}\text { Specialist } \\
\text { surgical } \\
\text { workforce } \\
\text { density }\end{array}$ & $\begin{array}{l}\text { A minimum target of } \\
\text { at least } 20 \text { surgical, } \\
\text { anaesthesia and } \\
\text { obstetric physicians } \\
\text { per } 100000 \\
\text { population }\end{array}$ & $\begin{array}{l}\text { At least } 10800 \text { surgical, } \\
\text { anaesthesia and obstetric } \\
\text { physicians, with appropriate } \\
\text { service of public and private } \\
\text { sectors }\end{array}$ & $\begin{array}{l}6329 \text { surgical, anaesthesia } \\
\text { and obstetric physicians } \\
\text { registered in the country. } \\
\text { Accurate division of time } \\
\text { between public and private is } \\
\text { unknown. Spectrum of non- } \\
\text { specialist physicians capable } \\
\text { of 'Bellwether procedures' } \\
\text { unknown }\end{array}$ & $\begin{array}{l}\text { SAMaSS will include } \\
\text { layering of practising } \\
\text { registered physicians } \\
\text { onto interactive map as } \\
\text { described above. } \\
\text { The South African Society } \\
\text { of Anaesthesiologists } \\
\text { is currently engaged } \\
\text { in a workforce, service } \\
\text { delivery and equipment } \\
\text { survey which may better } \\
\text { characterise facility and } \\
\text { personal provision (Safe } \\
\text { Surgery SA available at } \\
\text { www.ansa.org.za). } \\
\text { Engagement with medical } \\
\text { protection societies and } \\
\text { provincial departments } \\
\text { of health to determine } \\
\text { on-specialist personnel } \\
\text { capacity. }\end{array}$ \\
\hline $\begin{array}{l}\text { Surgical } \\
\text { volume }\end{array}$ & $\begin{array}{l}\text { Tracking of surgical } \\
\text { volume by } 2030 ; \text { a } \\
\text { minimum of } 5000 \\
\text { procedures per } 100 \\
000 \text { population by } \\
2030\end{array}$ & $\begin{array}{l}\text { National tracking of surgical } \\
\text { volumes, with at least } 2700 \\
000 \text { procedures per annum }\end{array}$ & $\begin{array}{l}\text { World Bank statistics of } \\
4852 \text { surgeries per } 100000 \\
(2012)^{44}\end{array}$ & $\begin{array}{l}\text { Small multicentre } \\
\text { prospective cohort studies } \\
\text { such as SASOS }{ }^{45} \text { and } \\
\text { GlobalSurg }(\mathrm{SA})^{17} \text { allow } \\
\text { a current indication of } \\
\text { volumes and outcomes. } \\
\text { Further studies, including } \\
\text { the Surgical Access } \\
\text { and Volume Evaluation } \\
\text { study, leveraging a network } \\
\text { of community service } \\
\text { doctors around the country } \\
\text { will aim to address these } \\
\text { gaps. }\end{array}$ \\
\hline
\end{tabular}


Table 1 Continued

\begin{tabular}{|c|c|c|c|c|}
\hline $\begin{array}{l}\text { LCoGS } \\
\text { indicator }\end{array}$ & $\begin{array}{l}\text { LCoGS time bound } \\
\text { target for } 2030\end{array}$ & $\begin{array}{l}\text { Time bound target adapted } \\
\text { for South Africa } \\
\text { (calculated on a population } \\
\text { of } 54 \text { million) }\end{array}$ & Current status of data & $\begin{array}{l}\text { Plans arising from the } \\
\text { NFSASA and research } \\
\text { networks in South Africa }\end{array}$ \\
\hline POMR & $\begin{array}{l}\text { Tracking of POMR } \\
\text { by } 2030 \text {; in } 2020 \text {, } \\
\text { evaluate global data } \\
\text { and set national } \\
\text { targets for } 2030\end{array}$ & $\begin{array}{l}\text { National tracking of POMR } \\
\text { in all levels of hospitals. } \\
\text { Eventual prospective tracking } \\
\text { of POMR and complications }\end{array}$ & $\begin{array}{l}\text { SASOS }^{45} \text { found a } 3.1 \% \text { in- } \\
\text { hospital mortality. } \\
\text { GlobalSurg (SA) }{ }^{17} \text { found a } \\
13.5 \% \text { in-hospital mortality } \\
\text { rate following intra-peritoneal } \\
\text { general surgery and a } 33.6 \% \\
\text { complication rate }\end{array}$ & $\begin{array}{l}\text { Small multicentre } \\
\text { prospective cohort studies } \\
\text { such as SASOS, }{ }^{45} \text { ASOS }^{30} \\
\text { and GlobalSurg (SA) }{ }^{17} \\
\text { allow a current indication } \\
\text { of volumes and outcomes. } \\
\text { Further collaborative } \\
\text { networks to prospectively } \\
\text { continually gather these } \\
\text { data are required. } \\
\text { The South African } \\
\text { Perioperative Research } \\
\text { Group identified } \\
\text { establishment of a national } \\
\text { database of critical } \\
\text { care outcomes as their } \\
\text { first priority for surgical } \\
\text { research. }\end{array}$ \\
\hline $\begin{array}{l}\text { Protection } \\
\text { against } \\
\text { impoverishing } \\
\text { expenditure }\end{array}$ & $\begin{array}{l}100 \% \text { protection } \\
\text { against } \\
\text { impoverishment } \\
\text { from out-of- } \\
\text { pocket payments } \\
\text { for surgical and } \\
\text { anaesthesia care by } \\
2030\end{array}$ & $\begin{array}{l}\text { Identification of areas where } \\
\text { out-of-pocket payments for } \\
\text { surgical and anaesthesia care } \\
\text { occur in public sector }\end{array}$ & $\begin{array}{l}\text { World Bank statistics of } 50 \% \\
\text { of people at risk }(2014)^{47}\end{array}$ & $\begin{array}{l}\text { South Africa's relatively } \\
\text { unique situation of } \\
\text { means testing for all } \\
\text { government healthcare } \\
\text { provision means that } \\
\text { these figures, derived from } \\
\text { a model encompassing } \\
\text { other African countries, }\end{array}$ \\
\hline $\begin{array}{l}\text { Protection } \\
\text { against } \\
\text { catastrophic } \\
\text { expenditure }\end{array}$ & $\begin{array}{l}100 \% \text { protection } \\
\text { against catastrophic } \\
\text { expenditure from } \\
\text { out-of-pocket } \\
\text { payments for } \\
\text { surgical and } \\
\text { anaesthesia care by } \\
2030\end{array}$ & $\begin{array}{l}\text { Identification of areas where } \\
\text { catastrophic expenditure } \\
\text { from out-of-pocket payments } \\
\text { for surgical and anaesthesia } \\
\text { care occurs in public sector }\end{array}$ & $\begin{array}{l}\text { World Bank statistics of } \\
25.5 \% \text { of people at risk } \\
(2014)^{48}\end{array}$ & $\begin{array}{l}\text { may not be accurate. This } \\
\text { highlights the importance } \\
\text { of accurate locally obtained } \\
\text { information. } \\
\text { In addition, the complex } \\
\text { dynamics of government } \\
\text { and private health systems } \\
\text { in South Africa, including } \\
\text { patient choice of service, } \\
\text { mean this is a complex } \\
\text { indicator to scrutinise. } \\
\text { Engagement with civil } \\
\text { society, public health } \\
\text { entities and academic } \\
\text { departments is still ongoing } \\
\text { to determine the best } \\
\text { methods to assess these } \\
\text { indicators in South Africa. }\end{array}$ \\
\hline
\end{tabular}

LCoGS, Lancet Commission on Global Surgery; NFSASA, National Forum on Surgery and Anaesthesia in South Africa; PEASC, Programme for Equitable Access to Surgical Care; POMR, perioperative mortality rate; SAMaSS, South African Map to Safe Surgery; SASOS, South African Surgical Outcomes Study.

created in the Department of Surgery at the University of the Witwatersrand with the primary aim of initiating the collection of data points towards the LCoGS indicators or identifying where processes for collection are in place.

Further to this national effort, the international collaboration between regions and countries undergoing this audit process of surgical provision through the LCoGS allows identification of successful methodology in other countries. This may be used to model and guide strategies for improving surgical and anaesthesia care in South Africa, with the aim of further standardisation internationally. Two available audit tools, the LCoGS Tool (http://www.lancetglobalsurgery.org/\#!implementation-tools/tx1dd) and the WHO Tool for Situational Analysis to Assess Emergency and Essential Surgical Care, have been adopted and adapted for this purpose. 
Patient outcomes are influenced by a myriad of variables: direct and indirect barriers to surgical diagnosis and care, adequacy of operative and perioperative care, and long-term postoperative follow-up. Successful examples of outcome studies are the Perinatal Problem Identification Programme and 'Saving Mothers' confidential enquiries, which have helped characterise perinatal and maternal mortality, including identification of haemorrhagic and other surgical complications. ${ }^{29}$ Neglected fields such as in general surgical procedures and in postoperative care areas (ward/high care/intensive care unit/rehabilitation) need further characterisation. ${ }^{30}$ The simple surgical 'Bellwether procedures' (caesarean section, laparotomy and open fractures) identified by the LCoGS ${ }^{4}$ can be considered primary indicators for the success of the entire surgical system in South Africa. The same outcome-based variables in these procedures measured and remeasured at the same hospitals over time will quantify quality improvement in surgical and anaesthesia care in South Africa. Areas requiring audit will include access to surgery, district hospital service delivery, staff competencies at all levels, budgets, facility resources and government engagement. Results of continuous audit should provide reliable indication as to South Africa's progress towards achieving the six LCoGS indicators by $2030{ }^{4}$

In addition to large-scale, observational, pragmatic studies designed to document the incidence and timeline of disease presentations and subsequent complications, smaller detailed projects identifying specific causes for specific inadequacies in surgical care can be complementary in providing information. All these types of studies benefit from interdisciplinary multicentre collaborations made possible with effective novel technology integration and feedback. ${ }^{31}$ Important stakeholders essential to the process include clinicians from university clinical departments and public health specialists, nursing departments and organisations, and healthcare professional societies. The second group of role players are specific research groups already working in these areas, leading national and international agendas. Some of these are summarised in box 2.

Box 1 Strategies for research to advance global surgical and anaesthesia care in South Africa

1. Appropriate and progressive research objectives

a. LCoGS indices as discussed in table 1

2. Use of established research programs

a. Identifying unpublished data nationwide from conference proceedings

b. Linking up similar studies from different centres

3. Adopting internationally consistent or harmonised data points

a. Maternal mortality

b. Outcomes for 'Bellwether procedures'

4. Using and expanding established collaborative outcome-based surgical research networks in South Africa (box 2)
Box 2 Collaborative networks in South Africa

Recent collaborative outcomes-based surgical research networks in South Africa

1. South African Surgical Outcomes Study: currently provides prospective data on perioperative mortality for regional and tertiary hospitals but is lacking for district hospitals. ${ }^{45}$

2. African Surgical Outcomes Study: measured perioperative complications and mortality in South Africa in March 2016, with a larger representation of district hospitals and using the surgical complications definitions from the International Surgical Outcomes Study (ISOS). ${ }^{49}$ With little data from Africa, having surgical outcomes data consistent with the 46000 patients from ISOS will ensure international comparability and enable the development of definitions for outcome measures for clinical effectiveness research in perioperative medicine.

3. GlobalSurg: a network of over 3000 clinicians across 67 countries $^{1750}$ including South Africa

a. GlobalSurg 1 identified variations in outcome after emergency intra-abdominal surgery across international settings in order to determine whether globally relevant quality improvement strategies are needed within acute surgical units ${ }^{50}$

b. GlobalSurg (SA): A local subanalysis of South African centres identified key hospital-specific and patient-specific risk factors for perioperative mortality and length of stay. ${ }^{5}$

c. GlobalSurg 2 (manuscript in preparation) will document surgical site infection rates after laparotomy.

4. South African Perioperative Research Group: recently identified the top 10 National Priorities for Perioperative Research in South Africa, using a Delphi process. ${ }^{46}$

5. National Committee for Confidential Enquiries into Maternal Deaths in South Africa: 'Saving Mothers' reports have identified and spearheaded change at a national level in maternity practice to prevent deaths from caesarean section.

Finally, in South Africa, there is a wealth of as yet unpublished literature presented over the last decade at the national conferences of surgical and related specialities. Current work is ongoing to identify current research, strengthen analysis and prevent duplication by linking similar studies in different centres and recognise nascent researchers to integrate into collaborative works.

Workforce and training: a national workforce must be shaped and mobilised to suit specific environments and resources

The health worker crisis in the sub-Saharan region has numerous dimensions. In addition to the described public/private disparity, the population and doctor density across South Africa still shows a major rural/ urban inequity. ${ }^{32}$ The national surgical care work force must meet the needs of the whole country and specific focus needs to be put on factors that pull medical staff into rural facilities.

South African studies have been undertaken to establish the needs of rural doctors in South Africa and to seek possible solutions to their problems. Although those studies have identified some of the major problems, implementation of the solutions to these issues is still required. Box 3 describes some factors suggested by rural 
Box 3 Factors to improve recruitment and retention of workforce ${ }^{25325354}$

- Hospital budget planning to make doctors posts available

- Improved availability of posts currently 'frozen' due to hospital budget constraints

- Effective human resources strategies to facilitate application, appointment and transfer of staff

- Improvement in salaries, leave benefits

- Upgraded hospital accommodation and recreational facilities

- Recognition of rural medicine practitioners with career progression and continuing professional development

- Increased support by specialists, rural referral systems, up-referral sites and tertiary hospitals

- Ensure the availability of essential medical services and medicines

- Improvement in the hospital environment and hospital infrastructure

- Strengthening of management and increase doctor involvement in management

doctors, which require urgent attention to retain them in their current rural practices.

The Department of Health in South Africa has attempted to address the shortage of rural doctors by introducing various interventions, including an increase in salaries and the introduction of scarce skills and rural allowances, mandatory community service for all health workers, deployment of foreign-trained doctors and upgrade of clinics and hospitals. Despite these, the maldistribution of doctors working in South Africa has not improved significantly. This attests to the multifactorial nature of this problem, requiring sustained efforts to rectify it. Resolving one isolated factor without improving the host of push factors currently present in the health system cannot lead to significant improvements in the retention of rural doctors. Government legislative attempts to redistribute doctors such as the provision of a certificate of need prior to opening a private practice have been unsuccessful and unpopular with individual doctors and the professional societies ${ }^{27}$ and highlights the importance of the professional societies in ensuring workforce plans are acceptable and implementable.

In South Africa, the government's Programme of Action on Human Resources has laid emphasis on accelerating staff appointment into vacant positions to reduce the staffing crisis and to reduce workloads prioritising financial and non-financial incentives. Although it has been shown in numerous studies that financial incentives are less important to non-financial incentives to retain staff, ${ }^{25334}$ the combined approach of both financial and non-financial incentives has been successful in rural regions of Kenya, Malawi, Lesotho and Swaziland. ${ }^{24}$ Novel local schemes enabling learners from rural areas to succeed in healthcare courses at tertiary institutions, through mentorship during training followed by integration into the local workforce on graduation, have also shown some success ${ }^{35}$ as well as offering provincial bursaries to students and requiring them to return to repay the bursary. ${ }^{36} 37$
A strong message from the participants of the NFSASA was the lack of interaction between rural and tertiary clinicians. A community of professionals who provide a reliable network of support for one another also aids in recruitment and retention in rural areas ${ }^{32}$ and is critical for the success of a National Surgical Plan in South Africa. This can only be established with adequate numbers of generalists and specialists (a challenge in a system currently burdened by a shortage of health professionals) and through effective communication and task sharing with strong relationships between district and regional hospitals.

Part of this network is explicit support for clinical staff when things go wrong within set scopes of practice. This requires accountability, review of the morbidities and mortalities and accreditation of facilities to perform appropriate surgical procedures. It is crucial that staff should be well supervised in their clinical practice and that providing service and training in these hospitals is mandatory for specialists. Redefining sites and providing 'joined-up' surgical care includes reframing traditional working practices. This will also require a marked improvement in information technology services to longitudinally track patients, establish hospital disease databases and ensure adequate referral. Retraining and upskilling of staff, which allows for easier 'down referral' of patients from regional care, should be done on site and in context by the appropriate specialists.

\section{Infrastructure and service delivery: strengthening the surgical system through the district hospital}

In addition to workforce provision, perhaps the biggest challenges of all will be improving access to life-saving surgery within 2 hours, a hallmark of universal surgical care. ${ }^{4}$ An aim of this should be to relieve tertiary facilities of 'non-specialist' operations, while ensuring patients have adequate access to specialist services. This must include transport and accommodation provision, which is an indirect barrier to accessing distance or specialist surgical services. The supplementary benefit, above that of the community receiving improved healthcare, is that local improved surgical care can lead to better economic development for the region. ${ }^{4}$ Failure to retain services and staff results in losses that primarily disadvantage poor, rural and underserved populations.

In South Africa, a governmental white paper outlining the proposed restructuring of health provision with a National Health Insurance (NHI) system details 'district healthcare teams ${ }^{38}$ responsible for service provision in a geographical area. These district clinical teams (DCTs) comprise a family physician, a PHC nurse, an obstetrician and gynaecologist, an advanced midwife, a paediatrician, a paediatric nurse and an anaesthetist to oversee emergency and perioperative care. They will have a clinical and an administrative role in maintaining clinical services, auditing services and predicting growth based on infrastructure and finance access. ${ }^{38}$ These teams do not explicitly have surgical specialists, but the integration 
of surgical care into the NHI can be achieved by establishing surgical care centres where populations are currently placed, with the adequate infrastructure to provide suitable surgical care, and direct routes of rapid bidirectional referral between district and regional (tertiary) surgical care.

Furthermore, the South African Department of Health wishes that minor surgery should be available at all district hospitals. However, as the Deputy Minister of Health noted, ' $\ldots$ as soon as minor surgery requires a general anaesthetic, there is an immediate escalation of the risk. Even with a "simple caesarean section", anaesthesia remains high risk'. ${ }^{39}$ This latter comment is borne out in the Confidential Enquiries into Maternal Deaths in South Africa ${ }^{40}$ The development of 'district' or 'rural' surgery into an acute specialty, encompassing surgical, obstetric and anaesthetics competency, would form the basis of district hospital care and would integrate into the DCT model. The level of competency required of the LCoGS 'Bellwether procedures' would also allow provision of other procedures, which are common to the primary hospital context such as intercostal drain placement, incisions and drainages of abscesses, management of haemorrhoids, circumcisions, evacuations of the uterus, spinal anaesthesia, rapid sequence inductions and emergency airway management.

The development of rural surgical care as a specialty would require a paradigm shift. The traditional hierarchy between specialists and generalists can be replaced by the diverse but harmonised skill sets between pathology-specific (traditional) specialists and new geographical (rural/ district surgery) specialists. Filling this gap in rural care at present is the family physician practising in rural district hospitals. Family medicine specialists are integral to a move to holistic surgical care, and although the scope of practice of a rural surgeon should be differentiated from that of a family physician, increasing the skill set of family physicians may be part of this solution (task sharing). To facilitate this, South African tertiary education facilities should include rotations in rural or district-level surgery where trainees, either undergraduate students or postgraduate in the relevant current specialities, are exposed to emergency surgical cases and gain competency in the 'Bellwether procedures'.

Despite many of these changes to the scope of specialist care, shortages in numbers remain problematic. Alternatives to the traditional route of medical student to doctor to specialist have been considered in many parts of the world and particularly successful in areas of need. A recent addition to medical training in South Africa is the Bachelor of Clinical Associate Degree, which has the capacity for rapid training, and is particularly appropriate for students who have an interest in staying within their communities. ${ }^{41}$ The opening of postgraduate diplomas of anaesthesia and surgery to non-MBBCh degree holders may further facilitate upskilling while candidates remain in practice. It also allows for competency-based practice and skills development rather than hierarchical practice based on level or type of healthcare provider.

This skills sharing, task sharing and upskilling is also imperative in allied medical and nursing care. Training platforms for all staff who will be involved with surgery and anaesthesia should be improved so as to ensure that there are enough allied health professionals trained in theatre, perioperative and critical care skills-especially with regards to specialist nurses. ${ }^{25}$ This will complement the current structure, which includes many career medical officers with high levels of surgical and anaesthetics skills ensuring continuous professional development and create opportunities for career progression and greater job satisfaction. Furthermore, the focus of training in surgical care has historically been on operative interventions and perioperative care. Although operative interventions are important, all parties involved with provision of these services should be integrated into holistic patient care and preventative medicine with a public health policy approach incorporating the social determinants of health and the contributions that are made by poor lifestyle choices such as reckless driving, alcohol abuse, obesity and smoking, which increase the likelihood and risk of surgery.

\section{Leadership and finance: the essential place for healthcare managers locally and nationally to partner with clinicians in reform}

Perhaps the most critical group of key players in changing surgical care in South Africa are from governmental organisations, and it is important to recognise the essential place of healthcare managers partnering with clinicians in reform. This includes hospital managers at a district and tertiary level in South Africa, the Office of Health Standards and Compliance and the National Department of Health. Quality improvement guidelines have been developed with varying degrees of implementation. Participation across the board is essential to impact patients' access to hospitals, for accurate institutional data and to ensure the integrity of the surgical and anaesthetics care data in South Africa. During his speech at the NFSASA, the Deputy Minister for Health, himself a doctor, acknowledged that the Department of Health's vision of 'a long and healthy life for all' could not be achieved without reviewing '...the essential package of surgical and anaesthetics services that are-and should be available-especially at district and regional hospitals in the country. ${ }^{39}$

Financing such radical changes in surgical service provision is hard, and any National Surgical Plan will only be successful if fully and realistically costed. Calls for widescale financial investments in the current economic climate are difficult, and access to 'new money' beyond the current budget may be challenging. Creative and innovative ways to use the current resources available in South Africa need to be found. At present, the National Treasury budget has specific programmes for HIV/AIDS, child and maternal health and violence and trauma among others. ${ }^{42}$ However, it was noted by the representative from the Treasury at 
the NFSASA that a surgical programme has never been requested. Identifying surgical care to the National Treasury as an area for specialised budget allocation must be a priority in order to ensure dedicated funding. A major aspect will be developing a workforce payment structure, which makes rural practice incentivised.

\section{CONCLUSION}

The National Forum for Surgery and Anaesthesia in South Africa concluded that radical transformation to the surgical frame work in South Africa has to occur in order to meet the surgical needs of the population. Crafting a solution for equitable surgical care in South Africa can be achieved through innovative collaborative data generation and dynamic implementation strategies within South Africa.

In the South African context, surgery and anaesthesia have to take their place as an essential component of Primary Healthcare within the imperative of universal health coverage. South Africans need to have access to life-saving emergency surgical care at the closest point of presentation and yet have equitable access to the tertiary specialties providing life-saving care at a different level. This dual priority is intuitive to clinicians but needs to be protected when changing the model of service delivery to one which prioritises primary care. It requires a paradigm shift in re-establishing the competence of district hospitals, upskilling their staff and allowing ease of up-referral and down-referral of patients to the centre best equipped to provide appropriate care and alleviating the current heavy burden on tertiary services.

The first step in the development of the National Surgical Plan is to document South Africa's current situation. This has the dual outcome of establishing data points for continued audit and establishing the network of collaborative clinicians collecting these points, dedicated to improving safe and affordable surgical provision. The establishment of the LCoGS indicators and tools developed from that will be critical for standardisation of audits in service delivery and serve as criteria for measurement of performance. These have been the objectives followed in this year following the NFSASA, and these ongoing efforts are highlighted in table 1.

Arising from the NFSASA, there has also been increased engagement crossing discipline, geographical and academic boundaries. The Programme for Equitable Access to Surgical Care (www.PEASC.org) has been established and started engaging with important stakeholders, including rural doctors and clinical associates societies, clinicians who previously had little engagement with surgery specialists. Discussions with clinicians and governmental leaders from other countries engaged in this process has also ensured insights into methodology and pitfalls around this process. Following analysis of the data points being established, primarily through mapping services and determining volume, the next step will be furthering governmental engagement, through the Department of Health and, crucially, Treasury towards a fully costed National Surgical Plan.

The NFSASA, stimulated by the LCoGS, has provided the impetus for change in surgical provision in South Africa. The recognition of timely equitable access to surgical care nationwide by all stakeholders aims to set a roadmap for major reform, guided by research, supported by professional bodies and academic institutions and implemented by government improving surgical care, thus ensuring 'a long and healthy life for all South Africans'.

Correction notice This paper has been amended since it was published Online First. Owing to a scripting error, some of the publisher names in the references were replaced with 'BMJ Publishing Group'. This only affected the full text version, not the PDF. We have since corrected these errors and the correct publishers have been inserted into the references.

Acknowledgements The authors particularly acknowledge the contribution of the working group on research from the National Forum on Surgery and Anaesthesia to the research section of this report: Bruce Biccard, Sarah Rayne, Tinashe Chandauka, Kathryn Chu, Damian Clarke, Jane Doherty, Mike Klipin, Vered Lack, Astrid Leusink, Mkhululi Lukhele, Emmanuel Makasa, Gwinyai Masukume, Pino Mavengere, Miriam Mutebi, Phumudzo Ndwambi, Nosipho Ntsabo, Jones Omoshoro-Jones, Ronell Parkhurst, John Scott, Mark Shrime and Allison Silverstein.

Contributors SR: study concept, literature search, analysis and interpretation, manuscript writing and final editing. SB: literature search, analysis and interpretation, and manuscript writing. SvS: literature search, analysis and interpretation, and manuscript writing. BB: study concept, analysis and interpretation, manuscript writing and final editing. MJP: study concept, analysis and interpretation, manuscript writing and final editing. MS: study concept, analysis and interpretation, manuscript writing and final editing.

Competing interests None declared.

Provenance and peer review Not commissioned; externally peer reviewed.

Data sharing statement No additional data are available.

Open Access This is an Open Access article distributed in accordance with the Creative Commons Attribution Non Commercial (CC BY-NC 4.0) license, which permits others to distribute, remix, adapt, build upon this work non-commercially, and license their derivative works on different terms, provided the original work is properly cited and the use is non-commercial. See: http://creativecommons.org/ licenses/by-nc/4.0/

(C) Article author(s) (or their employer(s) unless otherwise stated in the text of the article) 2017. All rights reserved. No commercial use is permitted unless otherwise expressly granted.

\section{REFERENCES}

1. Debas HT, Donkor P, Gawande A, et al. Essential surgery. Disease Control Priorities. 1. 3rd edn. Washington, DC: World Bank, 2015.

2. Kim J. Address at the launch of the Lancet Commission on Global Surgery by president of World Bank. 2014.

3. World Health Organization. Strengthening emergency and essential surgical care and anaesthesia as a component of universal health coverage Report by the Secretariat. 2014 http://apps.who.int/gb/ ebwha/pdf_files/EB135/B135_3-en.pdf.

4. Meara JG, Leather AJ, Hagander L, et al. Global surgery 2030: evidence and solutions for achieving health, welfare, and economic development. Lancet 2015;386:569-624.

5. National Assembly. Constitution of the republic of South Africa. 1994;38:70-7

6. South African National Planning Commission. National Development Plan: our future-make it work. 2012 http://www.gov.za/issues/ national-development-plan-2030.

7. South African National Planning Commission. Medium-term Strategic Framework, 2014-2019. 2014 http://www.poa.gov.za/ MTSF Documents/MTSF 2014-2019.pdf.

8. South African Department of Planning monitoring and evaluation. Outcome 2: a long and healthy life for all South Africans. 2012 
http://www.dpme.gov.za/keyfocusareas/outcomesSite/Pages/theOutcomes-Delivery-Agreements.aspx.

9. World Health Organization. Monitoring the building blocks of health systems: a handbook of indicators and their measurement strategies. 2010

10. Lozano R, Naghavi M, Foreman $\mathrm{K}$, et al. Global and regional mortality from 235 causes of death for 20 age groups in 1990 and 2010: a systematic analysis for the global burden of disease study 2010. Lancet 2012;380:2095-128.

11. Alkire BC, Vincent JR, Burns CT, et al. Obstructed labor and caesarean delivery: the cost and benefit of surgical intervention. PLoS One 2012;7:e34595.

12. Mangham-Jefferies L, Pitt C, Cousens S, et al. Cost-effectiveness of strategies to improve the utilization and provision of maternal and newborn health care in low-income and lower-middleincome countries: a systematic review. BMC Pregnancy Childbirth 2014;14:243.

13. Dorji WG, Aneni E, Blain O. A framework for estimating benefits of investing in maternal, newborn and child health. Report prepared by Susan Foster and Malcolm Bryant. Boston, MA: Department of International Health Boston University School of Public Health Partnership for Maternal, Newborn \& Child Health, 2013.

14. Torre LA, Bray F, Siegel RL, et al. Global cancer statistics, 2012. CA Cancer J Clin 2015;65:87-108.

15. Economist Intelligence Unit. Breakaway : the global burden of Cancer-challenges and opportunities. 2009

16. National Cancer Registry. Cancer in South Africa full report Johannesburg, South Africa: National Institute for Occupational Health , 2009.

17. Spence RT, Panieri E, Rayne SL. A multicentre evaluation of emergency abdominal surgery in South Africa: results from the GlobalSurg-1 South Africa study. S Afr Med J 2016;106:163-8.

18. Hardcastle TC, Samuels C, Muckart DJ. An assessment of the hospital disease burden and the facilities for the in-hospital care of trauma in KwaZulu-Natal, South Africa. World J Surg 2013;37:1550-61

19. Pillay-van Wyk V, Msemburi W, Laubscher R, et al. Mortality trends and differentials in South Africa from 1997 to 2012: second National Burden of Disease Study. Lancet Glob Health 2016;4:e642-53.

20. Alkire BC, Raykar NP, Shrime MG, et al. Global access to surgical care: a modelling study. Lancet Glob Health 2015;3:e316-e323.

21. The World Bank. specialist surgical workforce (per 100,000 population). http://data.worldbank.org/indicator/SH.MED.SAOP.P5? locations $=$ ZA.

22. van Rensburg HC. South Africa's protracted struggle for equal distribution and equitable access - still not there. Hum Resour Health 2014;12:26.

23. Nkomazana O, Mash R, Shaibu S, et al. Stakeholders perceptions on shortage of healthcare workers in primary healthcare in Botswana: focus group discussions. PLoS One 2015;10:e0135846

24. Dambisya MY. A review of non-financial incentives for health worker retention in east and southern Africa: Heal Syst Res Group, Dep Pharmacy, Sch Heal Sci Univ Limpopo, South Africa, 2007:1-65. http://www.chwcentral.org/sites/default/files/A review of nonfinancial incentives for health worker retention in east and southern Africa.pdf.

25. Zurn P, Dolea C, Stilwell B. Nurse retention and recruitment: developing a motivated workforce. Glob Nurs Rev Initiat 2005;4:1-36.

26. Mock CN, Donkor P, Gawande A, et al. Essential surgery: key messages from Disease Control Priorities, 3rd edition. Lancet 2015;385:2209-19.

27. le Roux KW, Couper I. Rural district hospitals-essential cogs in the district health system - and primary healthcare re-engineering. S Afr Med J 2015;105:440-1.

28. Pan African Association of Surgeons. Statement from the Pan African Association of Surgeons on the delivery of surgical services in sub-Saharan Africa. 2014 http://www.africansurgeons.com/ statement-from-the-pan-african-association-of-surgeons-on-thedelivery-of-surgical-services-in-sub-saharan-africa/.

29. Melarkode K, Cooper G, McClure J. Saving mothers' lives. Br J Anaesth 2008;100:561.
30. Biccard B, Madiba T, Pearse R. African Surgical Outcomes Study: ASOS study protocol. 2015:1-15 http://www.asos.org.za/ASOS protocol version 1 final.pdf.

31. Spence RT, Panieri E, Rayne SL, et al. Collaboration is key to strengthening surgical research capacity in sub-Saharan Africa. S Afr Med J 2016;106:125-6.

32. Kotzee TJ, Couper ID, Kotzee TJ, et al. What interventions do South African qualified doctors think will retain them in rural hospitals of the Limpopo province of South Africa? Rural Remote Heal [electronic Resour] 2006;6:581.

33. Wilson NW, Couper ID, De Vries E, et al. A critical review of interventions to redress the inequitable distribution of healthcare professionals to rural and remote areas. Rural Remote Health 2009;9:2.

34. Makapela NC, Useh U. Rural allowance and the retention of health professionals in selected hospitals in the North West Province of South Africa. J Hum Ergol 2013;44:129-38.

35. Friends of Mosvold. Mosvold Hospital-Ingwavuma. http://www. dpsa.gov.za/dpsa2g/documents/networks/Batho Pele LN 2007/ ARoss.pdf.

36. Department of Health, Republic of South Africa. Human Resources for Health South Africa 2030. 2011.

37. Department of Health, Republic of South Africa. A National Human Resources Plan for Health A National Human Resource Plan for Health An Accessible, Caring and High Quality Health System. 2006.

38. Naidoo S. The South African national health insurance: a revolution in health-care delivery!. J Public Health 2012;34:149-50.

39. Phaahla J. Address by the Deputy Minister of Health Dr Joe Phaahla on the Lancet Commission on Global Surgery. National Forum of Surgery and Anesthesia, Faculty of Health Sciences. Johannesburg, South Africa: University of the Witwatersrand, 2015.

40. Gebhardt GS, Fawcus S, Moodley J, et al. Maternal death and caesarean section in South Africa: results from the 2011-2013 Saving Mothers report of the National Committee for Confidential Enquiries into Maternal Deaths. S Afr Med J 2015;105:287-91.

41. Moodley S V, Wolvaardt L, Louw M, et al. Practice intentions of clinical associate students at the University of Pretoria, South Africa. Rural Remote Health 2014;14:1-12.

42. National Treasury of the republic of South Africa. Estimates of National Expenditure Abridged version. 2016.

43. Health Professions Council of South Africa. HPCSA Iregister. http:// isystems.hpcsa.co.za/iregister/.

44. World Bank. Number of surgical procedures (per 100,000 population) | data. http://data.worldbank.org/indicator/SH.SGR.PROC.P5?end= 2014\&start=2014\&view=map.

45. Biccard BM, Madiba TE. The South African Surgical Outcomes Study: a 7-day prospective observational cohort study. S Afr Med J 2015;105:465-75.

46. Biccard BM, Alphonsus CS, Bishop DG, et al. National priorities for perioperative research in South Africa. S Afr Med J 2016:106:485-8.

47. World Bank. Risk of catastrophic expenditure for surgical care $\%$ of people at risk) | data. http://data.worldbank.org/indicator/SH.SGR. CRSK.ZS?view=chart.

48. World Bank. Risk of impoverishing expenditure for surgical care (\% of people at risk) | data. http://data.worldbank.org/indicator/SH.SGR IRSK.ZS?view=chart.

49. Pearse R. International Surgical Outcomes Study (ISOS): international observational cohort study of complications following elective surgery. 2013;0:1-16.

50. GlobalSurg Collaborative. Mortality of emergency abdominal surgery in high-, middle- and low-income countries. Br J Surg 2016;103.

51. GlobalSurg-2. Determining the Worldwide Epidemiology of Surgical Site Infections After Gastrointestinal Surgery (GlobalSurg 2). 2015:1-14. Study registration number: GlobalSurg-2 Study protocol v7.5.

52. Moodley J, Mothers S. Sixth report on the Confidential Enquiries into Maternal Deaths in South Africa 2011-2013. 2013 www.doh.gov.za.

53. Uys LR, Awases M, Kamanzi D, et al. Review of nursing and midwifery programmes in Africa. Africa $J$ Nurs Midwifery 2006;8:3-14 http://search.ebscohost.com/login.aspx?direct=true\& AuthType $=i p$, shib\&db=jlh\&AN=2009316004\&site=ehost-live.

54. WHO, World Health Organization. The World Health Report 2006: working together for health. 2006. 